\title{
Pengaruh Tayangan Televisi, Celebrity Endorsement, Terhadap Citra Merek (Brand Image) Kosmetik "Maybelline"
}

\section{Karnila Ali}

Universitas Muhammadiyah Metro, Lampung, Indonesia

*email: karnila.ali85@gmail.com

\begin{tabular}{|c|c|}
\hline$A R T I C L E \quad I N F O$ & $A B S T R A C T$ \\
\hline $\begin{array}{l}\text { Artikel History: } \\
\text { Received:December 28, } 2020 \\
\text { Revised:January 30, } 2021 \\
\text { Published:February 8, } 2021\end{array}$ & $\begin{array}{l}\text { Cosmetics can already be regarded as a necessity which will further determine its } \\
\text { consumption choices with a variety of cosmetic brands both domestically and abroad. } \\
\text { Consumers make considerations based on the brand's image, product prices, product quality, } \\
\text { and others.The purpose of this study to determine television advertising impressions affect the } \\
\text { Maybellien cosmetics brand image, to find out celebrity endorsement affect maybellien } \\
\text { cosmetics brand image and to find out between television advertisement shows and celebrity }\end{array}$ \\
\hline $\begin{array}{l}\text { Keywords: } \\
\text { Celebrity Endorsement, Brand } \\
\text { Image, Television Advertising } \\
\text { Impressions }\end{array}$ & $\begin{array}{l}\text { endorsements simultaneously affect the brand image Maybelline cosmetics. } \\
\text { This research method is quantitative. The technique used in data collection in this study used } \\
\text { observation, interview and questionnaire techniques. Then in analyzing data using } \\
\text { quantitative methods, i.e. the data collected is then analyzed. After the data is collected, then } \\
\text { the data is analyzed using multiple regression analysis and processed using SPSS. Based on } \\
\text { data analysis using SPSS, the conclusions of television commercials and celebrity } \\
\text { endorsement impressions simultaneously / simultaneously affect the brand image of } \\
\text { Maybelline Cosmetics in Management students of the Faculty of Economics and Business, } \\
\text { University of Muhammadiyah Metro University. }\end{array}$ \\
\hline I NFO A R T I K E L & A B S T R A K \\
\hline $\begin{array}{l}\text { Riwayat Artikel: } \\
\text { Diterima: } 5 \text { Desember } 2020 \\
\text { Direvisi: } 30 \text { Januari } 2021 \\
\text { Dipublikasikan: } 8 \text { Februari } 2021\end{array}$ & $\begin{array}{l}\text { Kosmetik sudah bisa dikatakan sebagai kebutuhan yang selanjutnya akan menentukan pilihan } \\
\text { konsumsinya dengan berbagai merk kosmetik baik dalam negeri maupun luar negeri. } \\
\text { Konsumen membuat pertimbangan berdasarkan citra merek, harga produk, kualitas produk, } \\
\text { dan lain-lain. Tujuan penelitian ini untuk mengetahui pengaruh tayangan iklan televisi } \\
\text { terhadap citra merek kosmetik Maybellien, mengetahui pengaruh endorsemen selebriti }\end{array}$ \\
\hline $\begin{array}{l}\text { Kata kunci: } \\
\text { Celebrity Endorsement, Citra } \\
\text { Merek, Tayangan Iklan Televisi }\end{array}$ & $\begin{array}{l}\text { terhadap citra merek kosmetik maybellien, dan untuk mengetahui antara tayangan iklan } \\
\text { televisi dan celebrity endorsement secara simultan mempengaruhi citra merek kosmetik } \\
\text { Maybellien. } \\
\text { Metode penelitian ini adalah kuantitatif. Teknik yang digunakan dalam pengumpulan data } \\
\text { dalam penelitian ini menggunakan teknik observasi, wawancara dan angket. Kemudian dalam } \\
\text { menganalisis data dengan menggunakan metode kuantitatif, yaitu data yang terkumpul } \\
\text { kemudian dianalisis. Setelah data terkumpul, selanjutnya data tersebut dianalisis dengan } \\
\text { menggunakan analisis regresi berganda dan diolah menggunakan SPSS. Berdasarkan } \\
\text { perhitungan Uji } t \text {, maka kesimpulan iklan televisi dan tayangan celebrity endorsement secara } \\
\text { simultan berpengaruh signifikan dan positif dalam meningkatkan variable dependent brand } \\
\text { image kosmetik Maybelline. Dari hasil perhitungan Uji } f \text { yang diperoleh bahwa tayangan } \\
\text { iklan televisi dan celebrity endorsement berpengaruh signifikan terhadap citra merek pada } \\
\text { mahasiswi Manajemen Fakultas Ekonomi dan Bisnis Universitas Muhammadiyah } \\
\text { Metro. }\end{array}$ \\
\hline
\end{tabular}




\section{PENDAHULUAN}

Jumlah penduduk Indonesia sebesar 254 juta jiwa menjadikan Indonesia pasar yang menjanjikan untuk perusahaan kosmetik. Persaingan antar pasar industri perawatan pribadi dan kosmetik semakin kompetitif. Hal ini terbukti dengan banyaknya jenis kosmetik beredar baik produksi dalam negeri maupun produksi luar negeri. Membanjirnya produk kosmetik di pasaran mempengaruhi sikap seseorang terhadap keputusan pembelian dan pemakaian barang.

Target perusahaan kosmetik ini adalah kaum hawa, tetapi di zaman sekarang kaum adam sudah mulai memakai kosmetik juga. Perusahaan kosmetik berinovasi menciptakan produk-produk yang cocok digunakan oleh masyarakat di Indonesia.

Kosmetik sudah bisa dikatakan sebagai kebutuhan yang selanjutnya akan menentukan pilihan-pilihan konsumsinya dengan berbagai macam merek kosmetik baik produk dalam negeri maupun luar negeri. Sebelum menjatuhkan pilihan kepada satu merek kosmetik pasti konsumen sudah melakukan survei kecil-kecilan akan berbagai jenis merek yang beredar di pasaran, seperti citra akan merek itu sendiri, harga produk suatu merek itu dan lainnya. Konsumen melakukan pertimbangan berdasarkan citra merek itu, harga produk, kualitas produk, dan lainnya. Apabila citra merek, harga dan lainnya dirasakan sudah sesuai maka konsumen baru menjatuhkan pilihan kepada suatu merek.

Menurut Aaker (Sangadji, 2013:327) "citra merek adalah seperangkat asosiasi unik yang ingin diciptakan atau dipelihara oleh pemasar. Berbagai kelebihan dan daya tarik produk yang ditawarkan oleh setiap pemasar untuk memberikan kepuasan pada konsumen. Salah satu produk yang ditawarkan adalah produk-produk kosmetik. Salah satu kosmetik yang beredar di pasaran saat ini adalah "Maybelline"

Menurut Tjiptono (2008:226), Iklan memiliki empat fungsi utama, yaitu menginformasikan khalayak mengenai seluk beluk produk (informative), mempengaruhi khalayak untuk membeli (persuading), dan menyegarkan informasi yang telah diterima khalayak (reminding), serta menciptakan suasana yang menyenangkan sewaktu khalayak menerima dan mencerna informasi (enternainment). Untuk mendukung penyampaian iklan dan juga pembentukan citra produk, maka digunakan seorang endorser dalam iklan.

Shimp (2003:460) berpendapat bahwa celebrity endorser adalah menggunakan artis sebagai bintang iklan di media-media, mulai dari media cetak, media sosial, maupun media telivisi. Selain itu selebriti digunakan karena atribut kesohorannya termasuk ketampanan, keberanian, talenta, 
keanggunan, kekuatan, dan daya tarik fisiknya yang sering mewakili daya tarik yang diinginkan oleh merek yang mereka iklankan.

Penggunaan celebrity endorser dapat mempengaruhi citra merek pada suatu produk dan dapat juga digunakan untuk mendongkrak penjualan (Sulistya, 2012:11).

Berdasarkan perumusan masalah yang telah diajukan, maka penelitian ini bertujuan untuk mengetahui pengaruh tayangan iklan televisi terhadap citra merek kosmetik maybellien, pengaruh celebrity endorsement terhadap citra merek kosmetik maybellien, pengaruh antara tayangan iklan televisi dan celebrity endorsement secara simultan terhadap citra merek kosmetik Maybelline.

Pemasaran merupakan sistem total aktifitas bisnis yang dirancang untuk merencanakan, menetapkan harga, mempromosikan dan mendistribusikan produk, jasa dan gagasan yang mampu memuaskan keinginan pasar sasaran dalam rangka mencapai tujuan organisasi.

Menurut Daryanto (2011:6) pemasaran adalah suatu proses sosial dan manajerial dimana individu dan kelompok mendapatkan kebutuhan dan keinginan mereka dengan menciptakan, menawarkan, dan bertukar sesuatu yang bernilai satu sama lain.

Sebagian besar usaha untuk memenuhi kebutuhan dan keinginan manusia dilakukan melalui pemasaran, hal ini terutama disebabkan karena proses pemasaran menambah kegunaan (utilitas) dari produk yang ada, jadi proses pemasaran seperti pembelian, penjualan, pengangkutan, dan penggudangan, merupakan proses menambah kegunaan (utilitas) produk yang ada (Sofjan Assauri, 2013:17).

\section{Tayangan Iklan Televisi}

Pengertian iklan secara umum menjelaskan bahwa iklan merupakan bentuk penyampaian pesan sebagaimana kegiatan komunikasi yang mempunyai kekuatan yang sangat penting sebagai alat pemasaran yang membantu menjual barang, membiarkan layanan serta gagasan atau ide-ide melalui saluran tertentu (Widyatama, 2011:28).

Pengertian secara lebih mendalam mengenai definisi iklan televisi adalah sebuah dunia magis yang dapat mengubah komoditas ke dalam gemerlapan yang memikat dan mempesona menjadi sebuah sistem yang keluar dari imajinasi dan muncul ke dalam dunia nyata melalui media (Bungin, 2011:107). Di sisi lain iklan televisi adalah sebuah media untuk menjual barang atau jasa bukan menghibur dengan alasan bahwa sebuah iklan hanya melaporkan suatu barang atau jasa dan tidak ada hubungannya antara rasa suka kepada iklan-iklan yang ditayangkan (Bungin, 2011:121). 
Iklan televisi mampu mendorong satu trend berbahasa. Pesannya mudah diingat, karena bentuk pesan yang disampaikan memang pendek. Slogan iklan jarang yang membentuk kalimat. Kata-kata iklan yang paling mengena tak bias menjadi sebuah kalimat. Namun lebih banyak didasarkan pada pengemasan bahasa agar enak di dengar, atau mengikuti arus trend berbahasa yang tengah muncul. Iklan televisi dengan daya pikatnya telah menciptakan satu efisiensi dalam menjual produk. Ini memang tak lepas dari karakter media televisi.

Swastha (2002:245) menyebutkan fungsi iklan sebagai pemberikan informasi lebih banyak dari pada lainnya (baik tentang barangnya, harganya ataupun informasi lain) yang mempunyai kegunaan bagi konsumen, sebagai pembujuk atau mempengaruhi meyakinkan masyarakat akan kelebihan produknya sehingga masyarakat terpengaruh dan akhirnya melakukan tindakan pembelian, menciptakan kesan (image) untuk menciptakan iklan yang sebaik-baiknya (baik menggunakan warna, ilustrasi, bentuk dan layout yang menarik), memuaskan keinginan pembeli yang ingin mengetahui terlebih dahulu kelebihan dan kekurangan dari barang itu.

\section{Bintang Iklan (Celebrity Endorsment)}

Berkembangnya sebuah iklan tidak terlepas dari seorang artis pendukung (Celebrity Endorsement) dalam memasarkan atau mempromosikan produk dari perusahaan. Terutama penggunaan bintang iklan tersebut di tayangkan di sebuah media telivisi, hal ini merupakan strategi alternatif dan tepat untuk memperkenalkan sebuah produk kepada para konsumen.

Menurut (Kotler dan Keller, 2009:519) yang dikutip dalam jurnal (Wahyudin, 2016:12) Celebrity endorser merupakan penggunaan narasumber (source) sebagai figure yang menarik atau popular dalam iklan merupakan salah satu cara kreatif untuk menyampaikan pesan, agar pesan yang disampaikan dapat mencapai perhatian yang lebih tinggi dan dapat diingat.

Menurut Royan (2004:14), dalam penelitian Endang Sulistya (2012), indikator celebrity endorser terdiri dari 4 unsur, yaitu Visibility yang memiliki dimensi seberapa jauh popularitas selebriti, Credibility yang berhubungan dengan product knowledge yang diketahui sang bintang, Attraction lebih menitik beratkan pada daya tarik sang bintang, Power adalah kemampuan selebriti dalam menarik konsumen untuk membeli. 


\section{Citra Merek}

Merek berfungsi membedakan barang-barang yang dihasilkan oleh seorang produsen dengan produsen lainnya. Menurut American Marketing Association (AMA), merek adalah sebuah nama, istilah, tanda, symbol, atau desain, atau kombinasi semuanya, yang dimaksudkan untuk mengidentifikasikan barang-barang dan jasa-jasa dari seorang penjual atau sekelompok penjual dan untuk mendiferensiasikan mereka dari persaingan (Christina Ariadne Sekar Sari, 2017:194).

Citra merek (brand image) merupakan representasi dari keseluruhan persepsi terhadap merek dan dibentuk dari informasi dan pengalaman masa lalu terhadap merek itu. Citra terhadap merek berhubungan dengan sikap yang berupa keyakinan dan preferensi terhadap suatu merek. Konsumen yang memiliki citra yang positif terhadap suatu merek, akan lebih memungkinkan untuk melakukan pembelian (Setiadi, 2003:180).

Indikator Citra Merek Hoeffler dan Kotler (dalam Dipa, 2015:8) 1) Kesan Profesional, Produk atau jasa memiliki kesan profesional atau memiliki kesan dan keahlian dibidang apa yang dijual, 2) Kesan Modem, Produk atau jasa memiliki kesan modem atau memiliki teknologi yang selalu mengikuti perkembangan zaman, 3) Melayani Semua Segmen, Produk atau jasa mampu melayani semua segmen yang ada, tidak hanya melayani segmen khusus saja, 4) Perhatian Kepada Konsumen, Produk atau jasa dibuat produsen memberikan perhatian atau peduli pada keinginan dan kebutuhan konsumen.

\section{METODE PENELITIAN}

Jenis penelitian ini adalah penelitian lapangan (field research) yakni pengamatan langsung ke objek yang diteliti guna mendapatkan data yang relevan.

\section{Desain Penelitian}

Penelitian ini termasuk penelitian kuantitatif dimana peneliti dapat menentukan hanya beberapa variabel saja dari objek yang diteliti kemudian dapat membuat instrumen untuk mengukurnya (Sugiyono, 2006:17). Penelitian kuantitatif banyak dituntut menggunakan angka, mulai dari pengumpulan data, penafsiran terhadap data tersebut, serta penampilan dari hasilnya. Demikian juga pemahaman akan kesimpulan penelitian akan lebih baik apabila juga disertai dengan tabel, grafik, bagan, gambar atau tampilan lain (Arikunto, 2010:27). Data Primer data yang diperoleh langsung dari objek penelitian, berupa dokumen-dokumen dan laporan tertulis dari 
mahasiswi serta informasi lain yang ada hubungannya dengan masalah ini. Data Sekunder adalah data yang sudah diterbitkan atau digunakan pihak lain. Contohnya jurnal, referensi, media internet, majalah, dan publikasi lainnya.

\section{Populasi dan Sample}

Populasi dalam penelitian ini adalah dengan cara perhitungan statistik yaitu dengan menggunakan Rumus Slovin. Rumus tersebut digunakan untuk menentukan ukuran sampel dari populasi yang telah diketahui jumlahnya yaitu sebanyak 76 mahasiswi Manajemen Fakultas Ekonomi dan Bisnis Universitas Muhammadiyah Metro. Berdasarkan perhitungan tersebut maka jumlah sampel pada penelitian ini adalah 64 mahasiswi Manajemen Fakultas Ekonomi dan Bisnis Universitas Muhammadiyah Metro.

\section{Definisi Operasional}

Penyusunan kisi-kisi instrumen penelitian didasarkan pada variabel dan indikator penelitian yang ada. Adapun kisi-kisi kuesioner pada penelitian ini dapat dilihat pada tabel berikut:

Tabel 1 Kisi-kisi Kuesioner Penelitian

\begin{tabular}{ll|ll}
\hline No. & Variabel & Indikator & No. Soal \\
\hline 1. & Tayangan Iklan & Memberikan informasi & 1,2, \\
& Televisi $\left(\mathrm{X}_{1}\right)$ & Mempengaruhi & \\
& & Menciptakan kesan & $3,4,5,6$ \\
& & & $7,8,9,10,11$ \\
& & & $12,13,14,15$ \\
& & \\
\hline 2. & Celebrity & Pepularitas (Visibility) & 1,2 \\
& Endorsement $\left(\mathrm{X}_{2}\right)$ & Kredibilitas (Credibility) & $3,4,5$ \\
& & Daya Tarik (Attraction) & $6,7,8,9,10,11,12$ \\
& Kemampuan (Power) & $13,14,15$ \\
\hline 3. & Citra merek (brand & Kesan profesional & $1,1,5,6$, \\
& image) (Y) & Kesan modern & $2,5,6,11$ \\
& & Melayani semua segmen & $7,8,9,11$ \\
& Perhatian kepada konsumen & \\
& & $3,4,10,12,13,14,15$ \\
\hline
\end{tabular}

Sumber: Data diolah penulis, 2019

\section{Alat Analisis}

Analisis kuantitatif ini digunakan untuk mengetahui pengaruh tayangan iklan televisi dan celebrity endorsement terhadap citra merek pada mahasiswi Manajemen Fakultas Ekonomi dan Bisnis Universitas Muhammadiyah Metro dengan menggunakan rumus analisis regresi linier berganda:

$$
\mathrm{Y}=\mathrm{a}+\mathrm{b}_{1} \mathrm{X}_{1}+\mathrm{b}_{2} \mathrm{X}_{2}+\mathrm{e}
$$


Persamaan di atas menganalisis citra merk (y), dengan ketergantungan atau hubungan antara:

$\mathrm{X}_{1} \quad$ : tayangan iklan televisi

$\mathrm{X}_{2} \quad$ : celebrity endorsement

a : Konstanta

$\mathrm{b}_{1} \quad$ : koefisien $\mathrm{X}_{1}$

$\mathrm{b}_{2} \quad$ : koefisien $\mathrm{X}_{2}$

e : error

\section{HASIL DAN PEMBAHASAN}

Analisis yang digunakan untuk menguji hipotesis dalam penelitian ini menggunakan analisis regresi linear berganda. Regresi linear berganda digunakan untuk mengetahui pengaruh variabel independen terhadap variabel dependen.

Tabel 2. Hasil Uji Analisis Regresi Berganda

Coefficients $^{\mathrm{a}}$

\begin{tabular}{|c|c|c|c|c|c|c|}
\hline & & \multicolumn{2}{|c|}{$\begin{array}{l}\text { Unstandardized } \\
\text { Coefficients }\end{array}$} & \multicolumn{2}{|c|}{$\begin{array}{l}\text { Standardized } \\
\text { Coefficients }\end{array}$} & \multirow[b]{2}{*}{ Sig. } \\
\hline \multicolumn{2}{|c|}{ Model } & $\mathrm{B}$ & Std. Error & Beta & $\mathrm{t}$ & \\
\hline \multirow[t]{3}{*}{1} & (Constant) & 23.119 & 5.309 & & 4.355 & .000 \\
\hline & Tayangan Iklan Televisi & .188 & .094 & .288 & 1.996 & .050 \\
\hline & Celebrity Endorsement & .465 & .137 & .491 & 3.400 & .001 \\
\hline
\end{tabular}

Sumber: Data diolah spss, 2020

Berdasarkan hasil pengujian pada tabel 2 di atas, maka dapat diuraikan sebagai berikut:

$$
\mathrm{Y}=\alpha 23,119+\mathrm{X}_{1} 0,188+\mathrm{X}_{2} 0,465+\mathrm{e}
$$

Penjelasan dari persamaan tersebut dapat dijelaskan sebagai berikut:

1. Nilai (constant) menunjukkan nilai sebesar 23,119. Artinya jika tidak dipengaruhi oleh tayangan iklan televisi $\left(\mathrm{X}_{1}\right)$, celebrity endorsement $\left(\mathrm{X}_{2}\right)$ maka besarnya nilai citra merek $(\mathrm{Y})$ adalah sebesar 23,11\%.

2. Koefisen regresi $\mathrm{X}_{1}$ bernilai sebesar 0,188 menunjukkan bahwa setiap penambahan sebesar 1 pada tayangan iklan televisi $\left(\mathrm{X}_{1}\right)$ akan mempengaruhi citra merek $(\mathrm{Y})$ sebesar 18,8\%.

3. Koefisen regresi $\mathrm{X}_{2}$ bernilai sebesar 0,465 menunjukkan bahwa setiap penambahan sebesar 1 pada celebrity endorsement $\left(\mathrm{X}_{2}\right)$ akan mempengaruhi citra merek $(\mathrm{Y})$ sebesar 46,5\%. 
Berdasarkan hasil analisis regresi linier berganda tersebut, telah diketahui nilai masingmasing variabel bebas terhadap variabel terikatnya. Maka dapat disimpulkan bahwa variabel bebas yang paling dominan mempengaruhi dalam meningkatkan variabel terikat yaitu celebrity endorsement $\left(\mathrm{X}_{2}\right)$. Hal ini terbukti dengan didapatkannya nilai koefisien regresinya pada celebrity endorsement $\left(\mathrm{X}_{2}\right)$ yang paling besar dibandingkan variabel lain yaitu 0,465 atau sebesar 46,5\% citra merek dapat dipengaruhi oleh celebrity endorsement pada mahasiswi Manajemen Fakultas Ekonomi dan Bisnis Universitas Muhammadiyah Metro.

\section{Uji T (Parsial)}

Uji t dimaksudkan untuk mengetahui secara parsial variabel independen berpengaruh signifikan terhadap variabel dependen yaitu tayangan iklan televisi terhadap citra merek dan celebrity endorsement terhadap citra merek serta dengan syarat dapat dikatakan berpengaruh signifikan jika sig < $\alpha(0,05)$. Hasil uji t dapat dilihat pada Output Coefficient dari hasil analisis regresi linier berganda dengan menggunakan bantuan program SPSS versi 16. Pengujian penelitian ini dilakukan dengan tingkat keyakinan 5\% melalui ketentuan sebagai berikut:

Jika $t_{\text {hitung }}>t_{\text {tabel }}(0,05)$, maka $\mathrm{H}_{\mathrm{a}}$ didukung, dan $\mathrm{H}_{\mathrm{o}}$ tidak didukung

Jika $\mathrm{t}_{\text {hitung }}<\mathrm{t}_{\text {tabel }}(0,05)$, maka $\mathrm{H}_{\mathrm{a}}$ tidak didukung dan $\mathrm{H}_{\mathrm{o}}$ didukung

\section{Berdasarkan perhitungan Uji t pada tabel 4.3 diperoleh hasil yaitu:}

1) Variabel biaya promosi dengan tingkat signifikansi $5 \%(\alpha=0,05)$ sebesar $0,050 \neq 0,05$ dan $t_{\text {hitung }}(1,996)>t_{\text {tabel }}(1,671)$, maka $\mathrm{H}_{\mathrm{a}}$ didukung dan $\mathrm{H}_{\mathrm{o}}$ tidak didukung, sehingga secara parsial variabel tayangan iklan televisi berpengaruh positif dan signifikan terhadap citra merek Kosmetik Maybelline pada mahasiswi Manajemen Fakultas Ekonomi dan Bisnis Universitas Muhammadiyah Metro yang berarti bahwa hasil penelitian sesuai dengan hipotesis yang berbunyi tayangan iklan televisi berpengaruh positif dan signifikan terhadap citra merek.

2) Variabel biaya distribusi dengan tingkat signifikansi 5\% $(\alpha=0,05)$ sebesar $0,001<0,05$ dan $t_{\text {hitung }}(3,400)>t_{\text {tabel }}(1,671)$, maka $H_{a}$ didukung dan $H_{o}$ tidak didukung, sehingga secara parsial variabel celebrity endorsement berpengaruh positif dan signifikan terhadap citra merek Kosmetik Maybelline pada mahasiswi Manajemen Fakultas Ekonomi dan Bisnis Universitas Muhammadiyah Metro yang berarti bahwa hasil penelitian sesuai dengan hipotesis yang berbunyi celebrity endorsement berpengaruh positif dan signifikan terhadap citra merek. 


\section{Uji F (Simultan)}

Uji F dimaksudkan untuk mengetahui pengaruh signifikansi antara variabel independen dan variabel dependen secara simultan yaitu pengaruh tayangan iklan televisi dan celebrity endorsement terhadap citra merek dengan syarat dapat dinyatakan berpengaruh signifikan jika sig $<\alpha(0,05)$. Pengujian penelitian ini dilakukan dengan kriteria sebagai berikut:

Jika $\mathrm{F}_{\text {hitung }}>\mathrm{Ft}_{\text {tabel }}(0,05)$, maka $\mathrm{H}_{\mathrm{a}}$ didukung, dan $\mathrm{H}_{\mathrm{o}}$ tidak didukung

Jika $\mathrm{F}_{\text {hitung }}<\mathrm{F}_{\text {abel }}(0,05)$, maka $\mathrm{H}_{\mathrm{a}}$ tidak didukung dan $\mathrm{H}_{\mathrm{o}}$ didukung

Tabel 3 Uji Simultan

ANOVA $^{\mathrm{b}}$

\begin{tabular}{llllll|l}
\hline Model & & Sum of Squares & df & Mean Square & F & Sig. \\
\hline 1 & Regression & 423.292 & 2 & 211.646 & 37.514 & $.000^{\mathrm{a}}$ \\
& Residual & 344.146 & 61 & 5.642 & & \\
& Total & 767.437 & 63 & & & \\
\hline
\end{tabular}

a. Predictors: (Constant), Celebrity Endorsement, Tayangan Iklan Televisi

b. Dependent Variable: Citra Merek

Sumber: Data primer diolah spss 2020

Berdasarkan tabel 3 memperlihatkan bahwa nilai $F_{\text {hitung }}$ sebesar 37,514 dengan nilai probabilitas $(\mathrm{sig})=0,000$. Nilai $\mathrm{F}_{\text {hitung }}(37,514)>\mathrm{F}_{\text {tabel }}(3,15)$ dan nilai sigma lebih kecil dari nilai probabilitas 0,000 atau nilai $0,000<0,05$ maka $\mathrm{H}_{\mathrm{a}}$ didukung dan $\mathrm{H}_{\mathrm{o}}$ tidak didukung yang berarti bahwa tayangan iklan televisi dan celebrity endorsement secara bersama-sama berpengaruh positif dan signifikan terhadap citra merek Kosmetik Maybelline pada mahasiswi Manajemen Fakultas Ekonomi dan Bisnis Universitas Muhammadiyah Metro.

\section{Uji Koefisien Determinasi $\left(\mathbf{R}^{2}\right)$}

Uji ini bertujuan untuk melihat kesesuaian model atau seberapa besar kemampuan variabel bebas dalam menjelaskan varians variabel terikatnya. Dari proses perhitungan diperoleh hasil koefisien determinasi sebagai berikut: 
Tabel 4 Hasil Koefisien Determinasi $\left(\mathrm{R}^{2}\right)$

Model Summary ${ }^{\mathrm{b}}$

\begin{tabular}{lllll}
\hline Model & $\mathrm{R}$ & $\mathrm{R}$ Square & Adjusted R Square & Std. Error of the Estimate \\
\hline 1 & $.743^{\mathrm{a}}$ & .552 & .537 & 2.375 \\
\hline a. Predictors: (Constant), Celebrity Endorsement, Tayangan Iklan Televisi & \\
b. Dependent Variable: Citra Merek & &
\end{tabular}

Sumber: Data primer diolah spss 2020

Dari perhitungan diketahui nilai $\mathrm{R}$ square adalah 0,552 , hal ini membuktikan bahwa kemampuan variabel bebas dalam menjelaskan varians dari variabel terikatnya adalah sebesar $55,2 \%$. Berarti terdapat $44,8 \%$ varians variabel terikat yang dijelaskan oleh faktor lain yang tidak ada dalam penelitian ini.

\section{Pembahasan}

Dari hasil perhitungan uji $\mathrm{f}$ yang diperoleh bahwa tayangan iklan televisi dan celebrity endorsement berpengaruh signifikan terhadap citra merek Kosmetik Maybelline pada mahasiswi Manajemen Fakultas Ekonomi dan Bisnis Universitas Muhammadiyah Metro secara simultan.

Dari perhitungan uji t dimaksudkan untuk mengetahui masing-masing variabel independent yaitu tayangan iklan televisi dan celebrity endorsement berpengaruh signifikan dalam meningkatkan variabel dependent yaitu citra merek. Hasil dari masing-masing variabel dapat dijelaskan sebagai berikut:

1. Tayangan Iklan Televisi

Dari perhitungan uji $\mathrm{t}$ dapat dimaknai bahwa variabel independent tayangan iklan televisi berpengaruh signifikan dan positif dalam meningkatkan variabel dependent citra merek, hal ini disebabkan karena tayangan iklan televisi mempengaruhi citra merek Kosmetik Maybelline pada mahasiswi Manajemen Fakultas Ekonomi dan Bisnis Universitas Muhammadiyah Metro.

2. Celebrity Endorsement

Dari perhitungan uji $\mathrm{t}$ dapat dimaknai bahwa variabel independent celebrity endorsement berpengaruh signifikan dan positif dalam meningkatkan variabel dependent citra merek, hal ini disebabkan karena celebrity endorsement mempengaruhi citra merek Kosmetik Maybelline pada mahasiswi Manajemen Fakultas Ekonomi dan Bisnis Universitas Muhammadiyah Metro. 


\section{KESIMPULAN}

Variabel tayangan iklan televisi memberikan pengaruh terhadap citra merek Kosmetik Maybelline pada mahasiswi Manajemen Fakultas Ekonomi dan Bisnis Universitas Muhammadiyah Metro. Begitu pula celebrity endorsement memberikan pengaruh terhadap citra merek Kosmetik Maybelline pada mahasiswi Manajemen Fakultas Ekonomi dan Bisnis Universitas Muhammadiyah Metro. Tayangan iklan televisi dan celebrity endorsement berpengaruh secara bersamasama/simultan terhadap citra merek Kosmetik Maybelline pada mahasiswi Manajemen Fakultas Ekonomi dan Bisnis Universitas Muhammadiyah Metro. Dengan tayangan iklan dapat lebih membantu mahasiswi dalam mendapatkan informasi mengenai make up. Dan dengan adanya tayangan iklan mahasiswi Manajemen Fakultas Ekonomi dan Bisnis Universitas Muhammadiyah Metro lebih dapat mengenal dan mengingat citra merek Maybelline.

\section{DAFTAR PUSTAKA}

Aaker David, D. (1992). Measuring Audience Perceptions of Commercials and Relaating Them To Ad Impact. Journal Od Advertising Research.

Assauri, Sofjan. (2013). Manajemen Pemasaran. Jakarta: Rajawali Pers.

Basu, Swastha. (2002). Manajemen Pemasaran. Edisi Kedua. Cetakan Kedelapan. Jakarta: Penerbit Liberty.

Bungin, B. (2011). Metodologi Penelitian Kuantitatif: Komunikasi, Ekonomi dan Kebijakan Publik Serta Ilmu-Ilmu Sosial Lainnya. Jakarta: Kencana Prenaga Group.

Daryanto. (2011). Manajemen Pemasaran. Sari Kuliah. Bandung: Satu Nusa.

Dipa, Yoga. (2015). Pengaruh Kualitas Pelayanan terhadap Brand Image Restoran Koki Joni Pasta and Turkey Yogyakarta (Studi Kasus pada Konsumen Restoran Koki Joni Pastaand Turkey Yogyakarta). Yogyakarta: Universitas Sanata Dharma.

Endang Sulistya Rini dan Dina Widya Astuti, Pengaruh Agnes Monica Sebagai Celebrity Endorser Terhadap Pembentukan Brand Image Honda Vario, Jurnal Bisnis dan Manajemen, 2012.

Keller, P. (2009). Manajemen Pemasaran. Jakarta: Erlangga.

Royan, M. F. (2004). Marketing Selebrities. Jakarta: Elex Media Kompulindo.

Sari, Christiane Ariadne Sekar. (2017). Teknik Mengelola Produk dan Merek. Jakarta: Gramedia Pustaka Utama.

Setiadi, N. J. (2003). Perilaku Konsumen: Konsep dan Implementasi Untuk Strategi dan Penelitian Pemasaran. Jakarta: Kencana.

Shimp, T. (2003). Periklanan Promosi \& Aspek Tambahan Komunikasi Pemasaran. Jakarta: Erlangga.

Sugiyono. (2006). Metode Penelitian Kuantitatif, Kualitatif dan R \& D. Bandung: Alfabeta.

Suharsimi, Arikunto. (2010). Prosedur Penelitian Suatu Pendekatan Praktik. Jakarta: Rineka Cipta.

Tjiptono, F. (2008). Strategi Pemasaran. Yogyakarta: Andi.

Wahyuddin. (2016). Implementasi Kebijakan Alokasi Dana Desa di Desa Ako Kecamatan Pasangkayu Kabupaten Mamuju Utara. ISSN: 2302-2019, Volume 4 No. 5, Mei 2016.

Widiyatama, R. (2011). Teknik Menulis Naskah Iklan. Jakarta: Cakrawala 